\title{
Nocardia takedensis: a newly recognized pathogen responsible for skin and soft tissue infections
}

\author{
Romain Lotte ${ }^{1,2,3^{*}}$, Alicia Chevalier ${ }^{1 \dagger}$, Sabine Dantas ${ }^{4}$, Nicolas Degand ${ }^{1}$, Alice Gaudart ${ }^{1}$, \\ Pierre-Simon Rörhlich ${ }^{2,5}$, Laurent Boyer ${ }^{3}$, Veronica Rodriguez-Nava ${ }^{4}$, Pascal Del Giudice ${ }^{6}$ and Raymond Rui \\ $m y^{1,2,3}$
}

\begin{abstract}
Nocardia takedensis was first isolated in 2005, from soil in Japan. We report here two cases of lymphangitis in France (2012-2017) caused by N. takedensis both occurring after skin injury while gardening, which enabled its inoculation. The two patients were immunocompromised and successfully treated by an antimicrobial agent active on the isolated strain, trimethoprim-sulfamethoxazole and amoxicillin-clavulanic acid for patient one and patient two, respectively. Our study along with previous ones supports the idea of a newly recognized cutaneous opportunistic pathogen and reinforces the recommendation of using gloves during soil exposure for immunocompromised patients. Lastly, according to data found in the literature, we would recommend trimethoprim-sulfamethoxazole as an efficient empirical antibiotic therapy in case of cutaneous infection caused by N. takedensis.
\end{abstract}

Nocardia takedensis was first isolated from soil in 2005 [1]. The first isolation in human was reported in 2006 in Japan [2]. Since then, five cases of cutaneous Nocardiosis caused by $N$. takedensis have been described during a seven-year period (2010-2017): one in the US [3], one in Mexico [4], two in Asia [5, 6] and one in France [7] (Table 1). We report two cases of lymphangitis caused by $N$. takedensis both occurring after skin injury while gardening. The patients were both immunocompromised and living in Southeast France. We discuss the source of contamination, the global dissemination of this Nocardia species, and the measures to prevent infection.
*Correspondence: lotte.r@chu-nice.fr

${ }^{\dagger}$ Romain Lotte and Alicia Chevalier contributed equally to this work ${ }^{1}$ Department of Bacteriology, Nice Academic Hospital, Nice, France

Full list of author information is available at the end of the article

\section{Study}

Our study was performed in Nice Teaching Hospital, in Southeast France, during 1999-2019. A total of 50 isolates of Nocardia species were collected from 36 patients. The major types of infections were cutaneous infections (58\%), pulmonary infections (33\%) and bacteremia (9\%). During the study period, all the isolates were identified to the species level using $16 \mathrm{~S}$ rDNA gene sequencing as previously described [8].

For the two $N$. takedensis strains isolated from patient 1 and patient 2, blast analysis of the 1435 nucleotides amplicon both showed $99.6 \%$ identity to the $16 \mathrm{~S}$ rDNA sequence of $N$. takedensis CIP108681 ${ }^{\mathrm{T}}$. Phylogenetic positions of the two clinical strains within the genus Nocardia are shown in Fig. 1. The tree was obtained by neighbor-joining method using MEGA $\mathrm{X}$ software as previously described [9]. The two isolates and N. takedensis $\mathrm{CIP} 108681^{\mathrm{T}}$ were compared using a random amplified polymorphic DNA-polymerase chain reaction (RAPDPCR) with a coliphage M13 single stranded primer (5'-GAGGGTGGCGGCTCT-3). M13-PCR has been 


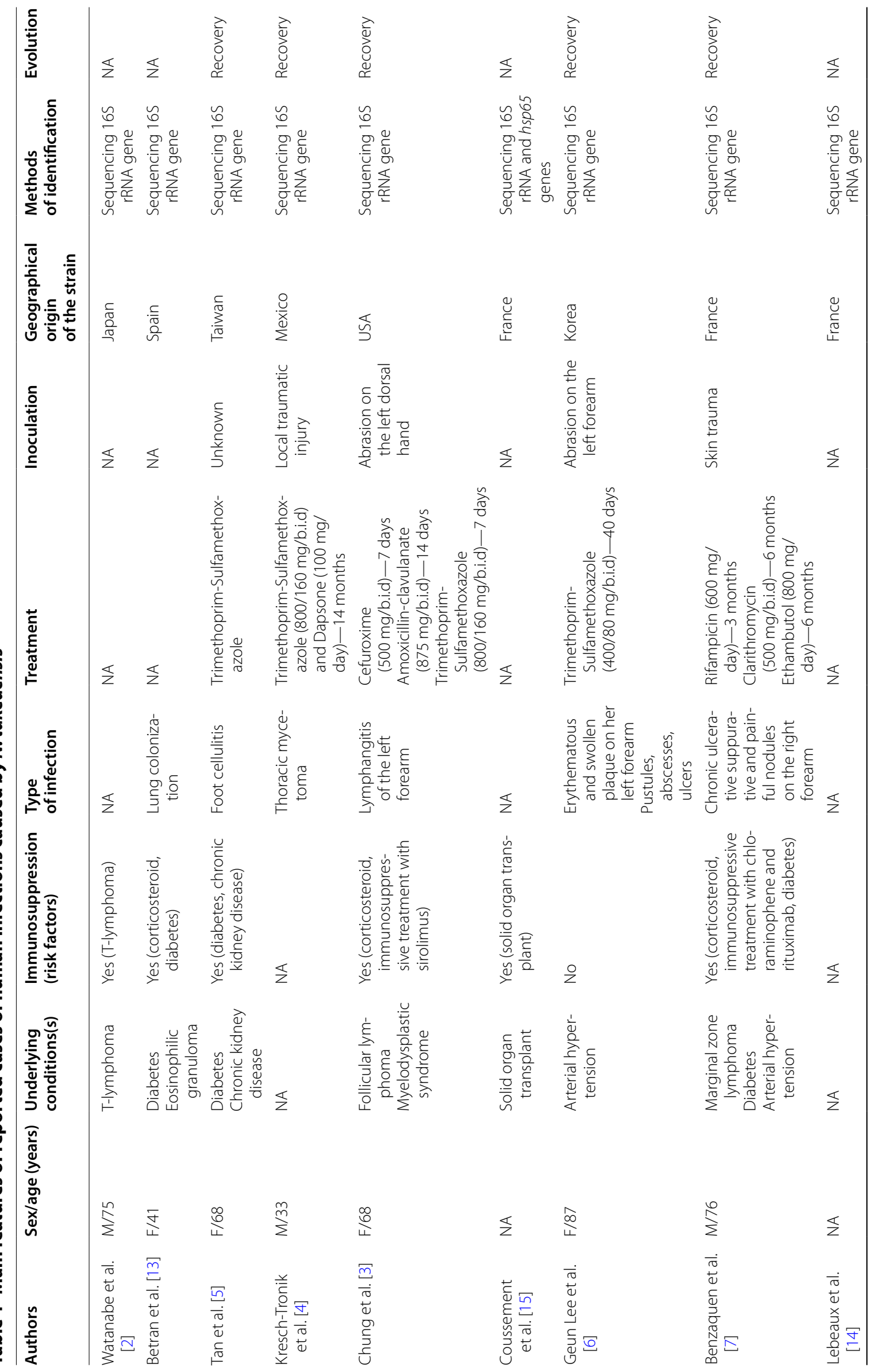




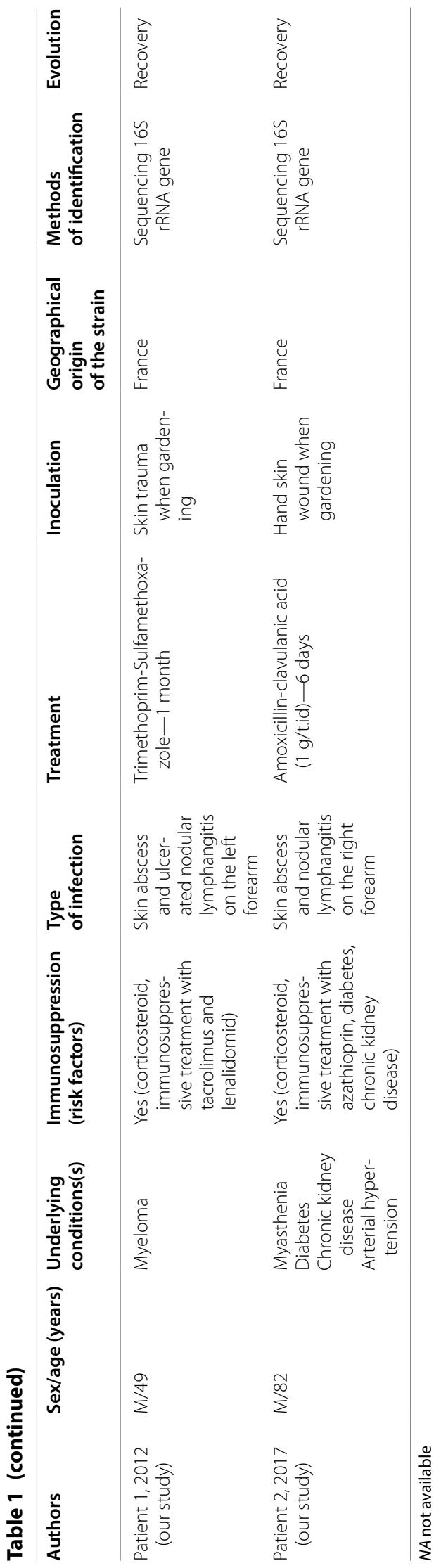


(See figure on next page.)

Fig. 1 Phylogenetic tree based on the 16S rDNA sequence of Nocardia strains isolated from patients 1 and 2. Phylogenetic positions of the Nocardia strains isolated from patient 1 and patient 2 within the genus Nocardia based on the $16 \mathrm{~S}$ rDNA sequences. The tree was obtained by Neighbor-joining method using MEGA X software [9]. Scale bar $(=0.01)$ indicates accumulated changes per nucleotide. The numbers next to the branches are the percentages determined in bootstrap analysis greater than 70\% (1,000 replicates). The number in parentheses are the accession

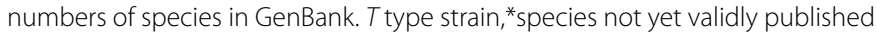

previously described by Guinebretière et al. for molecular typing of Bacillus cereus [10]. In the present work, this method was used to obtain and compare the RAPD-PCR profiles of $N$. takedensis isolates. Antibiotic susceptibility testing was performed using E-Test strips (bioMérieux) and CLSI interpretative standards for Nocardia spp.[11]. The two strains were sent to a French reference laboratory dedicated to Nocardia (French Observatory for Nocardiosis) to confirm AST results.

The first $N$. takedensis strain was isolated on November 19, 2012, from a 49 years-old male (patient 1) followed for a myeloma diagnosed in 2005. The patient had received allogeneic hematopoietic cell transplantation in 2008. In November 2012, he pricked his finger with a rose thorn while gardening at home without gloves in Fréjus (65 km from Nice). The patient attended the dermatology ward two weeks later, as a painful lesion had developed and spread from his hand to his left forearm. Physical examination by a dermatologist showed three inflammatory and painful ulcers distributed in a linear fashion, which suggested an ulcerated nodular lymphangitis with no regional adenopathy (Fig. 2). The body temperature was normal. The patient had an immunosuppressive therapy due to chronic GVHD (Graft-versus-host Disease) including prednisone $20 \mathrm{mg} /$ day and tacrolimus, and for relapse of myeloma he received lenalidomid $15 \mathrm{mg} /$ day and dexamethasone $40 \mathrm{mg} /$ week. A bacterial (pyogenic bacteria, atypical mycobacteria, Nocardia) or fungal infection was suspected. Whole-body computed tomography (CT) scan was performed and a systemic invasive infection was ruled out. Biopsy samples of the lesions were sent for analysis and a presumptive antibiotic treatment by levofloxacin was initiated. Microscopic histological examination showed specific infection markers. Both Gram and Ziehl-Neelsen staining were negative. Chlorazol black fungal staining did not retrieve any mycelial filament. After $72 \mathrm{~h}$, cultures on blood agar plates at $35{ }^{\circ} \mathrm{C}$ under $5 \% \mathrm{CO}_{2}$ remained negative. The antibiotic treatment by levofloxacin was stopped after 3 days because of suspicion of Quinolone-induced Achilles tendinopathy. The dermatologist then switched the treatment to trimethoprim-sulfamethoxazole as he suspected a cutaneous Nocardiosis based on the first microbiological results (negativity of standard cultures after 72 h). Coletsos medium (Bio-Rad ${ }^{\mathrm{TM}}$, Marnes-la-Coquette, France) seeded for detection of atypical mycobacteria, grew $N$. takedensis under aerobic conditions at $30{ }^{\circ} \mathrm{C}$ in 4 days. The patient showed a rapid reduction of pain and cutaneous lesions within a week after the introduction of cotrimoxazole. He was considered cured after 1 month of treatment. Clinical and paraclinical long-term followup (every 2 weeks for multiple myeloma) excluded a late relapse of the nocardial infection.

The second $N$. takedensis strain was isolated on November 24, 2017, from an 82-years-old immunocompromised male patient (patient 2) treated with prednisone $15 \mathrm{mg} /$ day and azathioprine $150 \mathrm{mg} /$ day for myasthenia since 2016. He was hospitalized in November 2017 to manage an acute ocular myasthenia with altered general conditions. Physical examination revealed a painless and non-itchy cutaneous abscess measuring $6 \mathrm{~mm}$ in diameter on the palmar face of his right hand with serous and hematic fluid, as well as a nodular lymphangitis on his right forearm. The body temperature was normal. A thorough interview of the patient revealed that this lesion had developed a few days before his admission, following a minimal hand skin wound when gardening at home without gloves in Menton (30 km from Nice). Laboratory investigations revealed an elevated $\mathrm{C}$-reactive protein (CRP) at $55 \mathrm{mg} / \mathrm{L}$. Whole-body CT scan excluded a systemic infection. Before starting the antibiotic treatment, a sterile swab was used to collect pus from the abscess. Gram staining did not show any microorganism. Swab cultures grew N. takedensis after $72 \mathrm{~h}$ of incubation both on blood agar plate (Oxoid, Dardilly, France) under aerobic atmosphere and on chocolate agar plate under $5 \% \mathrm{CO}_{2}$. The patient was discharged with a prescription of amoxicillin-clavulanic acid $1 \mathrm{~g} \mathrm{t}-\mathrm{i}-\mathrm{d}$ for 7 days. The wound completely healed 10 days after the beginning of this treatment. Long term hospital follow-up of this myasthenic patient (every two months) excluded a late relapse of the cutaneous Nocardiosis.

Both $N$. takedensis isolates displayed the same antimicrobial susceptibility pattern: susceptible to beta-lactams, trimethoprim-sulfamethoxazole, linezolid, amikacin, tobramycin and minocycline but resistant to ciprofloxacin and clarithromycin (Table 2). To date, data concerning $N$. takedensis susceptibility to antibiotics are scarce. Only 8 isolates have been tested (including our study) and were susceptible to trimethoprim-sulfamethoxazole in vitro and $100 \%$ of the patients treated by an antibiotic treatment including trimethoprim-sulfamethoxazole 


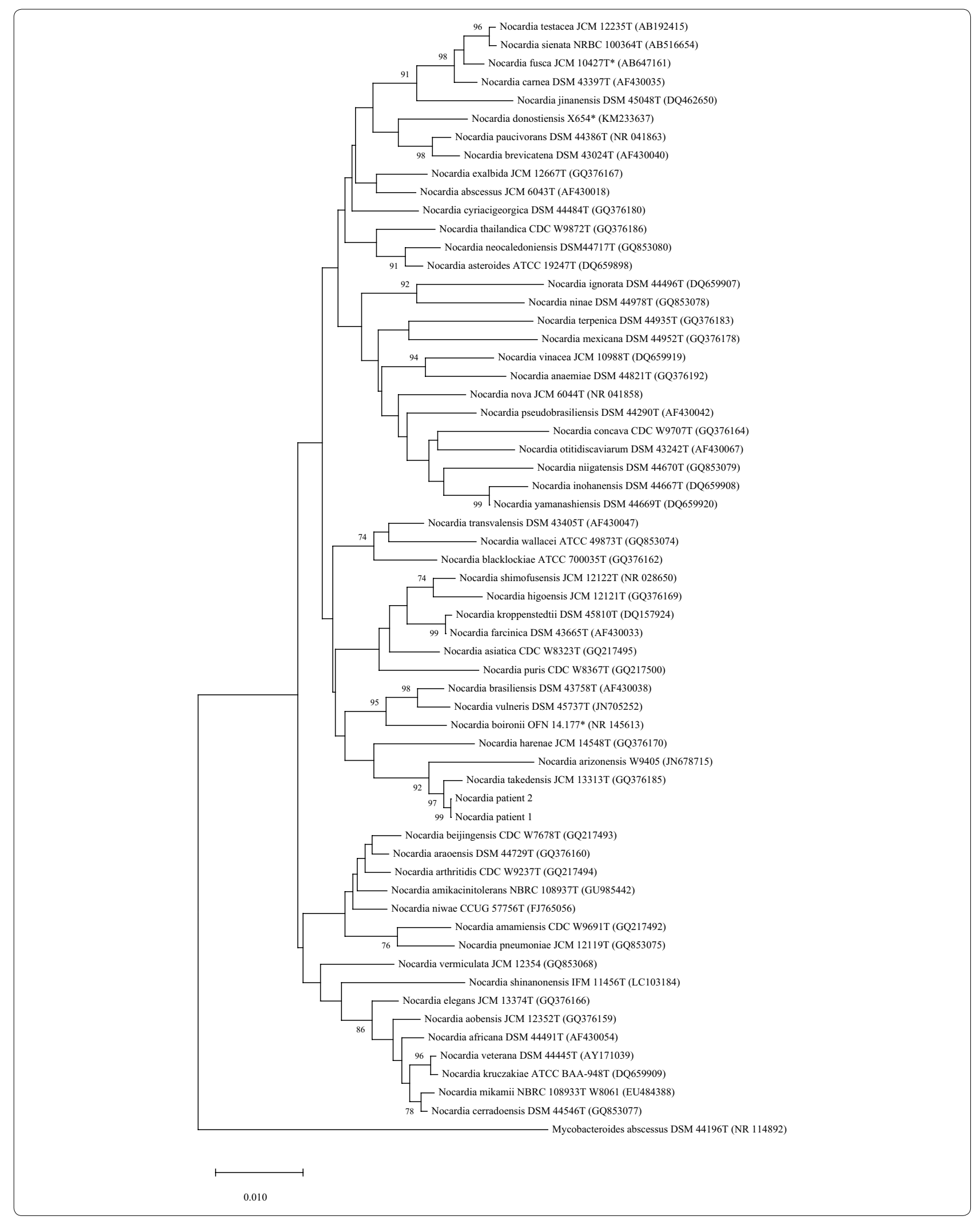




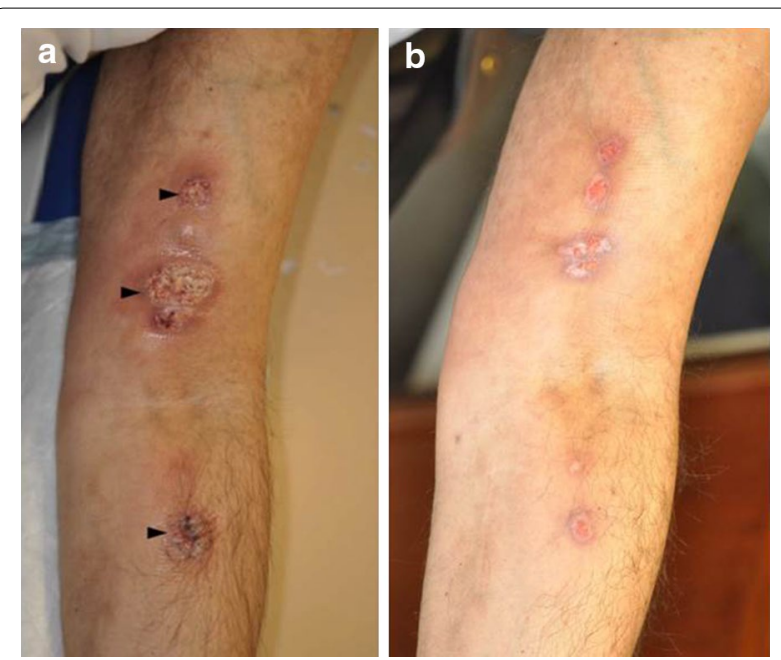

Fig. 2 Ulcerated nodular lymphangitis of the left arm and forearm of patient 1. a Painful linear ulcerated nodules of the left arm and forearm (arrowhead) (on the first day of antibiotic treatment). $\mathbf{b}$ Healed lesions three weeks later moat sediment and from sludge obtained from a sewage treatment plant. To date, only nine clinical isolates of $N$. takedensis have been reported in human [2-7, 13-15]. The main clinical and microbiological features of $N$. takedensis isolates are summarized in the Table 1. Including the two patients of our study, the mean patients' age was 64 years (33-87 years), with a sex ratio of 1.25. N. takedensis is mostly involved in primary cutaneous Nocardiosis, just as the closely related species $N$. brasiliensis is $[16,17]$. Indeed, seven out of eight infected patients (88\%) presented various forms of skin and soft tissue infections such as cellulitis, chronic skin ulceration, lymphangitis, or mycetoma, that occurred several days after a skin lesion allowing bacterial inoculation $[3-7,15$, our study]. In one patient $N$. takedensis was isolated from a respiratory specimen but without any clinical or radiological signs of pulmonary Nocardiosis, therefore corresponding to a transient pulmonary colonization [13]. For the last three clinical isolates reported in the literature, no clear and substantial data referring to the clinical cases were available $[2,14,15]$.

Table 2 Antimicrobial susceptibility testing determined using the E-test method

\begin{tabular}{|c|c|c|c|c|}
\hline \multirow[t]{2}{*}{ Antimicrobial agent } & \multicolumn{2}{|c|}{ Strain patient 1} & \multicolumn{2}{|c|}{ Strain patient 2} \\
\hline & $\mathrm{MIC}(\mu \mathrm{g} / \mathrm{ml})$ & Clinical categorization $^{a}$ & $\mathrm{MIC}(\mu \mathrm{g} / \mathrm{ml})$ & $\begin{array}{l}\text { Clinical } \\
\text { categorization }^{a}\end{array}$ \\
\hline Amikacin & 0.38 & $S$ & 1 & $S$ \\
\hline Amoxicillin-clavulanic acid & 6 & $S$ & 6 & $S$ \\
\hline Ceftriaxone & 1.5 & S & 0.25 & $\mathrm{~S}$ \\
\hline Ciprofloxacin & 32 & $\mathrm{R}$ & 2 & 1 \\
\hline Clarithromycin & 3 & $\mathrm{R}$ & 4 & $\mathrm{R}$ \\
\hline Imipenem & 0.25 & S & 0.125 & S \\
\hline Linezolid & 1.5 & $S$ & 0.19 & $S$ \\
\hline Minocycline & 1 & $S$ & 0.125 & S \\
\hline Trimethoprim-sulfamethoxazole & 0.047 & $S$ & 1 & $S$ \\
\hline Tobramycin & 0.75 & S & 3 & $\mathrm{~S}$ \\
\hline
\end{tabular}

a Interpretations of MICs in terms of susceptibility for Nocardia according to the criteria of CLSI [11].

completely recovered $[5,6,12,13]$. Therefore, we assume that this molecule could be used as an empirical antibiotic therapy in case of cutaneous Nocardiosis due to $N$. takedensis, before an AST is available.

The M13-PCR typing revealed that the two patients were infected by 2 different strains and excluded a clonal transmission between the 2 patients or a same origin of the strains. The two strains isolated in Southeast France were also different from the type strain $N$. takedensis CIP108681 ${ }^{\mathrm{T}}$ isolated in Japan (Fig. 3). N. takedensis was first characterized in 2005 by Yamamura et al. [1]. The two first reference strains of $N$. takedensis i.e. MS13t and AS4-2 were isolated in Japan respectively from a
Collectively, these cases of primary cutaneous nocardiosis reported in US [3], Mexico [4], Asia [5, 6], and Europe [7, our study], during 2010-2017 support the idea of $N$. takedensis as a newly recognized pathogen involved in skin infections. An interesting hypothesis is that climatic and soil conditions could have play a role in the environmental spread of this bacterial species. Indeed, in most of the cases published in the literature, $N$. takedensis strains were isolated in geographical area with favorable climatic conditions (South-East France, Spain, Korea, Japon, Taiwan or Mexico) [2, 4-7, 13, our study]. Moreover, Brown-Elliott et al., have previously suggested that Nocardia brasiliensis, a species that is phylogenetically 


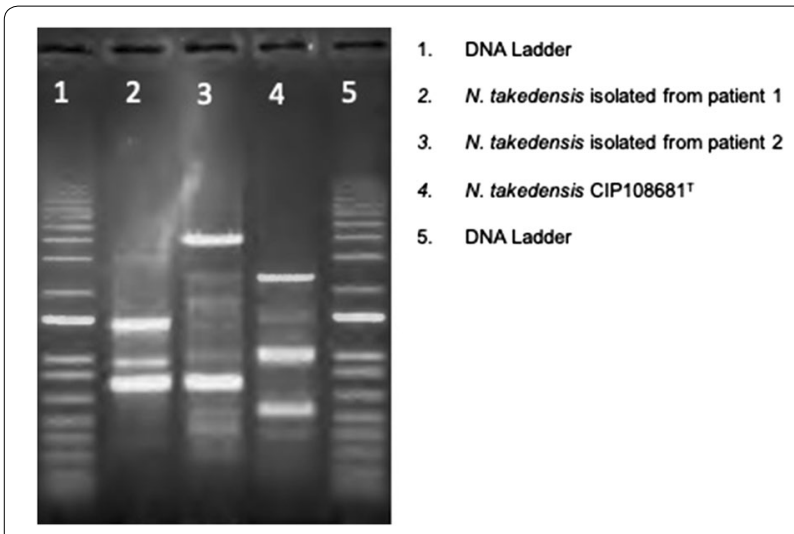

Fig. 3 Molecular typing using M13-PCR methods, as described by Guinebretière et al. [10]. Nocardia takedensis strains isolated from the two patients and Nocardia takedensis CIP108681 ${ }^{\top}$

closely related to $N$. takedensis, is predominantly isolated in tropical or subtropical region [16]. Recently, Lebeaux et al., showed a higher density of Nocardia isolates in the South of France and overseas territories than in other French areas, suggesting that environmental conditions may also increase the spread of Nocardia sp [14]. To date, data found in the literature concerning the potential impact of the climatic conditions on soil and on N. takedensis spreading are scarce and further studies will be necessary to assess this challenging hypothesis.

Concerning the source of contamination, it is likely possible that the two patients got infected by traumatic inoculation of $N$. takedensis present in the soil as both of them were gardening without gloves in the days preceding the onset of the symptoms. Furthermore, the two patients had received immunosuppressive drugs and corticosteroids which could have played a role in the infection. Immunosuppressive therapy or known risk factors of immunosuppression were found in all but one patient with N. takedensis infections (Table 1).

\section{Conclusions}

With the spread of $16 \mathrm{~S}$ rDNA sequencing, new Nocardia species have been recently described and the genus Nocardia currently encompasses more than 50 species involved in human diseases [16-18]. Besides, the rising number of patients receiving immunosuppressive therapies increases the risk of Nocardial infection through environmental exposure. Our study emphasizes the idea of $N$. takedensis as a newly recognized opportunistic pathogen responsible for skin infections. Infections occur after an inoculation following a cutaneous lesion. As this bacterium is found in the environment especially in soil, physicians should recommend their immunocompromised patients to wear shoes as well as clothing covering the skin when they are working in the soil (https://www.cdc.gov/nocardiosis/preve ntion/index.html). More, we would strongly recommend to immunocompromised patients to wear gloves when manipulating soil. This recommendation could also be extended to non-immunocompromised patient as primary cutaneous Nocardiosis has been repeatedly reported in this population. Lastly, because of the slow growth of Nocardia sp., prolonged culture conditions are required when a cutaneous Nocardiosis is suspected.

\section{Acknowledgements}

We thank Carole Besancon, Coralie Blanc, Sandrine Courtial, Sabrina Esposito and Sylvain Carpentier and the entire technician's team of the laboratory for their technical assistance. We also thank Emmanuelle Bergeron from the French Observatory of Nocardiosis.

\section{Authors' contributions}

RL: Wrote the manuscript and contributed to the acquisition of clinical and microbiological data. AC: Helped write the manuscript, drafted the manuscript and also contributed to collect the clinical and microbiological data. SD and VRN: Drafted the manuscript. Contributed to the acquisition of microbiological data. Performed control antimicrobial susceptibility tests on the strains at the French Observatory of Nocardiosis. ND and AG: Drafted the manuscript and performed antimicrobial susceptibility tests on the strains. PDG and PSR: Physicians in charge of patient one and patient two clinical follow-ups. Helped collect the clinical data. Drafted the manuscript. RR: Participated in the sequence alignment of the $16 \mathrm{~S}$ sequences of the patient's strain. Designed the study. Drafted the manuscript. All authors read and approved the final manuscript.

\section{Funding}

The authors received no financial support for this work.

\section{Availability of data and materials}

All datasets on which the conclusions of the manuscript rely are presented in the main paper and in the figures and tables.

\section{Consents to participate and ethic approval}

Informed consents to participate were obtained from the two patients that were reported in this article. Consents to publish were obtained from the two patients. For this retrospective observational study, ethics adherence was not required.

\section{Competing interests}

The authors declare that this work was not carried out in the presence of any personal, professional or financial relationships that could potentially be construed as a conflict of interest.

\section{Author details}

${ }^{1}$ Department of Bacteriology, Nice Academic Hospital, Nice, France. ${ }^{2}$ Université Côte D'Azur, CHU de Nice, Nice, France. ${ }^{3}$ Université Côte D'Azur, Inserm, C3M, Nice, France. ${ }^{4}$ Research Group On Bacterial Opportunistic Pathogens and Environment UMR5557 Écologie Microbienne, French Observatory of Nocardiosis, Institute of Infectious Agents, Hospices Civils de Lyon, Université de Lyon 1, CNRS, VetAgro Sup, Lyon, France. ${ }^{5}$ Department of Pediatric Hematology, Nice Academic Hospital, Nice, France. ${ }^{6}$ Department of Dermatology and Infectious Diseases, Centre Hospitalier Intercommunal, Fréjus-SaintRaphaël, Fréjus, France.

Received: 17 October 2019 Accepted: 9 August 2020

Published online: 20 August 2020

References

1. Yamamura H, Hayakawa M, Nakagawa Y, Tamura T, Kohno T, Komatsu F, et al. Nocardia takedensis sp. Nov., isolated from moat sediment and scumming activated sludge. Int J Syst Evol Microbiol. 2005;55:433-6. 
2. Watanabe K, Shinagawa M, Amishima M, lida S, Yazawa K, Kageyama A, et al. First clinical isolates of Nocardia carnea, Nocardia elegans, Nocardia paucivorans, Nocardia puris and Nocardia takedensis in Japan. J Med Mycol. 2006;47:85-9.

3. Chung E, Pulitzer MP, Papadopoulos EB, Papanicolaou GA, Babady NE, Marchetti MA. Lymphangitic papules caused by Nocardia takedensis. JAAD Case Rep. 2015;1:126-8.

4. Kresch-Tronik NS, Carrillo-Casas EM, Arenas R, Atoche C, Del Río-Ávila C, Ochoa-Carrera LA, et al. First case of mycetoma associated with Nocardia takedensis. J Dermatol. 2013;40:135-6.

5. Tan C-K, Lai C-C, Lin S-H, Liao C-H, Chou C-H, Hsu H-L, et al. Clinical and microbiological characteristics of Nocardiosis including those caused by emerging Nocardia species in Taiwan, 1998-2008. Clin Microbiol Infect. 2010;16:966-72

6. Lee TG, Jin WJ, Jeong WS, Moon SH, Kwon TG, Lee SK, et al. Primary cutaneous nocardiosis caused by Nocardia takedensis. Ann Dermatol. 2017;29:471-5.

7. Benzaquen M, Belenotti P, Lebowitz D, Drancourt M, Serratrice J. Primary cutaneous nocardiosis caused by Nocardia takedensis with pulmonary dissemination in an immunosuppressed patient. Australas J Dermatol. 2017;58:e97-e100.

8. Ruimy R, Breittmayer V, Elbaze P, Lafay B, Boussemart O, Gauthier M, et al. Phylogenetic analysis and assessment of the genera Vibrio, Photobacterium, Aeromonas, and Plesiomonas deduced from small-subunit rRNA sequences. Int J Syst Bacteriol. 1994:44:416-26.

9. Kumar S, Stecher G, Li M, Knyaz C, Tamura K. MEGA X: Molecular Evolutionary Genetics Analysis across computing platforms. Mol Biol Evol. 2018;35(6):1547-9.

10. Guinebretière M-H, Nguyen-The C. Sources of Bacillus cereus contamination in a pasteurized zucchini purée processing line, differentiated by two PCR-based methods. FEMS Microbiol Ecol. 2003:43:207-15.
11. Clinical and Laboratory Standards Institute. Susceptibility testing of mycobacteria, nocardiae, and other aerobic Actinomycetes; approved standard. CLSI document M24-A2. 2nd ed. Wayne, PA; 2011

12. Larruskain J, Idigoras P, Marimón JM, Pérez-Trallero E. Antibiotic Susceptibility of 186 Nocardia sp. isolates to 20 antimicrobial agents. Antimicrobia Agents Chemother. 2011;55(6):2995-8.

13. Betrán A, Rezusta A, Lezcano MA, Villuendas MC, Revillo MJ, Boiron P, et al. First Spanish case of nocardiosis caused by Nocardia takedensis. J Clin Microbiol. 2009;47:1918-9.

14. Lebeaux D, Bergeron E, Berthet J, Djadi-Prat J, Mouniée D, Boiron P, et al. Antibiotic susceptibility testing and species identification of Nocardia isolates: a retrospective analysis of data from a French expert laboratory, 2010-2015. Clin Microbiol Infect. 2018;25:489-95.

15. Coussement J, Lebeaux D, van Delden C, Guillot H, Freund R, Marbus S, et al. Nocardia infection in solid organ transplant recipients: a multicenter European case-control study. Clin Infect Dis. 2016;63:338-45.

16. Brown-Elliott BA, Brown JM, Conville PS, Wallace RJ. Clinical and laboratory features of the Nocardia spp. based on current molecular taxonomy. Clin Microbiol Rev. 2006;19:259-82.

17. Conville PS, Brown-Elliott BA, Smith T, Zelazny AM. The complexities of Nocardia taxonomy and identification. J Clin Microbiol. 2017;26:56.

18. Ruimy R, Riegel P, Carlotti A, Boiron P, Bernardin G, Monteil H, et al. Nocardia pseudobrasiliensis sp. nov., a new species of Nocardia which groups bacterial strains previously identified as Nocardia brasiliensis and associated with invasive diseases. Int J Syst Bacteriol. 1996;46:259-64.

\section{Publisher's Note}

Springer Nature remains neutral with regard to jurisdictional claims in published maps and institutional affiliations.
Ready to submit your research? Choose BMC and benefit from:

- fast, convenient online submission

- thorough peer review by experienced researchers in your field

- rapid publication on acceptance

- support for research data, including large and complex data types

- gold Open Access which fosters wider collaboration and increased citations

- maximum visibility for your research: over $100 \mathrm{M}$ website views per year

At BMC, research is always in progress.

Learn more biomedcentral.com/submissions 